\title{
RESEARCH
}

Open Access

\section{Fine-scale succession patterns and assembly mechanisms of bacterial community of Litopenaeus vannamei larvae across the developmental cycle}

Yanting Wang ${ }^{1,2+}$, Kai Wang ${ }^{1,2^{*}+}$ (D), Lei Huang ${ }^{1,2}$, Pengsheng Dong ${ }^{1,2}$, Sipeng Wang ${ }^{2}$, Heping Chen ${ }^{2,3}$, Zheng Lu ${ }^{4}$, Dandi $\mathrm{Hou}^{1,2}$ and Demin Zhang ${ }^{1,2^{*}}$

\begin{abstract}
Background: Microbiome assembly in early life may have a long-term impact on host health. Larval nursery is a crucial period that determines the success in culture of Litopenaeus vannamei, the most productive shrimp species in world aquaculture industry. However, the succession patterns and assembly mechanisms of larval shrimp bacterial community still lack characterization at a fine temporal scale. Here, using a high-frequency sampling strategy and $16 \mathrm{~S}$ rRNA gene amplicon sequencing, we investigated dynamics of larval shrimp bacterial community and its relationship with bacterioplankton in the rearing water across the whole developmental cycle in a realistic aquaculture practice.

Results: Alpha-diversity of larval shrimp bacteria showed a U-shaped pattern across the developmental cycle with the stages zoea and mysis as the valley. Correspondingly, the compositions of dominant bacterial taxa at the stages nauplius and early postlarvae were more complex than other stages. Remarkably, Rhodobacteraceae maintained the overwhelming dominance after the mouth opening of larvae (zoea l early postlarvae). The taxonomic and phylogenetic compositions of larval bacterial community both showed stage-dependent patterns with higher rate of taxonomic turnover, suggesting that taxonomic turnover was mainly driven by temporal switching among closely related taxa (such as Rhodobacteraceae taxa). The assembly of larval bacteria was overall governed by neutral processes (dispersal among individuals and ecological drift) at all the stages, but bacterioplankton also had certain contribution during three sub-stages of zoea, when larval and water bacterial communities were most associated. Furthermore, the positive host selection for Rhodobacteraceae taxa from the rearing water during the zoea stage and its persistent dominance and large predicted contribution to metabolic potentials of organic matters at post-mouth opening stages suggest a crucial role of this family in lavval microbiome and thus a potential source of probiotic candidates for shrimp larval nursery.

(Continued on next page)
\end{abstract}

\footnotetext{
*Correspondence: wangkai@nbu.edu.cn; zhangdemin@nbu.edu.cn

${ }^{\dagger}$ Yanting Wang and Kai Wang contributed equally to this work.

'State Key Laboratory for Managing Biotic and Chemical Threats to the

Quality and Safety of Agro-products, Ningbo University, Ningbo 315211

China

Full list of author information is available at the end of the article
}

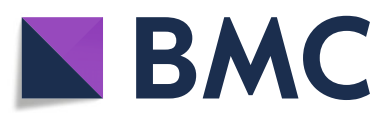

(- The Author(s). 2020 Open Access This article is licensed under a Creative Commons Attribution 4.0 International License, which permits use, sharing, adaptation, distribution and reproduction in any medium or format, as long as you give appropriate credit to the original author(s) and the source, provide a link to the Creative Commons licence, and indicate if changes were made. The images or other third party material in this article are included in the article's Creative Commons licence, unless indicated otherwise in a credit line to the material. If material is not included in the article's Creative Commons licence and your intended use is not permitted by statutory regulation or exceeds the permitted use, you will need to obtain permission directly from the copyright holder. To view a copy of this licence, visit http://creativecommons.org/licenses/by/4.0/. The Creative Commons Public Domain Dedication waiver (http://creativecommons.org/publicdomain/zero/1.0/) applies to the data made available in this article, unless otherwise stated in a credit line to the data. 
(Continued from previous page)

Conclusions: Our results reveal pronounced succession patterns and dynamic assembly processes of larval shrimp bacterial communities during the developmental cycle, highlighting the importance of the mouth opening stage from the perspective of microbial ecology. We also suggest the possibility and potential timing in microbial management of the rearing water for achieving the beneficial larval microbiota in the nursery practice.

Keywords: Shrimp larvae, Early life microbiome, Succession pattern, Community assembly, Host development

\section{Background}

The microbiota of animals is closely related to their health status [1, 2], nutrient metabolism [3-5], and immune system $[6,7]$. After animals' hatch or birth, their intestinal, skin, and oral microbial communities are gradually assembled. Microbial community assembly in early life may have a long-term impact on host health. Some studies have found that microbiome dysbiosis in infants and young children is associated with obesity [8], inflammatory bowel disease (IBD) [9], and immune diseases [10, 11]. In recent years, the relationship between the intestinal microbial community and the growth or health of aquatic invertebrates (such as shrimp) has been concerned [12-17]. As the most productive shrimp species in world aquaculture industry, the Pacific white shrimp (Litopenaeus vannamei) culture is mainly restricted by unstable quality of larvae and frequent outbreak of diseases [18-20]. Larval nursery, covering nauplius, zoea, mysis, and early postlarvae stages, is a crucial process that largely determines the success of Pacific white shrimp culture. The quality of larvae is closely related to the growth, development, and resistance to stress/disease of shrimps in subsequent culture stages [21]. At present, the Pacific white shrimp microbiome research is mainly focused on other growth stages (i.e., juvenile, sub-adult, or adult) in terms of their associations with outbreak of disease [15, 16, 22-24], growth [12, 25], and stress-resistance $[13,26]$. Furthermore, some studies have reported changes in the structure and function of the intestinal microbial community of postlarvae, juvenile and/or adult shrimp with development [17, 23, 27-30]. The understanding about how the microbiota of Pacific white shrimps functioning in their early life relies on revealing the succession and assembly mechanism of larval microbial community.

Intestinal microbiota of postlarvae, juvenile or adult shrimps could be determined by the developmental stage [17, 23, 27, 28, 30], genetic characteristics [14, 31], health status [17, 22-24], and habitat [13, 32, 33], and are commonly dominated by $\alpha$-Proteobacteria, $\gamma$-Proteobacteria, Firmicutes, Bacteroidetes and Actinobacteria [13, 23, 28, 33-35]. For example, Xiong et al. found that the relative abundance of $\alpha$-Proteobacteria decreased with the development of L. vannamei, but Actinobacteria showed an opposite trend [23]. In addition, many studies have found that Rhodobacteraceae taxa are ubiquitous in the intestinal microbiota of juvenile or adult shrimps [13, 23, 28, 34]. Some studies further observed the higher relative abundance of Rhodobacteraceae in the intestinal tract of healthy [17, 36, 37] and cold-resistant shrimps [13] compared with that of diseased and cold-vulnerable ones, respectively. Intestinal bacterial communities of juvenile or adult shrimps and bacterioplankton in the rearing water often significantly differ [17, 38, 39]. A recent work even demonstrated that very few shrimp intestinal bacteria were derived from the rearing water [38]. However, the bacterial community composition of larval shrimp and its relationship with habitat bacteria are unclear. To the best of our knowledge, only several studies have focused on the bacterial community of L. vannamei larvae. For example, Zheng et al. found that $\alpha$-Proteobacteria, $\gamma$-Proteobacteria, and Bacteroidetes species could be widely isolated from larval shrimp samples [40], while based on $16 \mathrm{~S}$ rRNA gene sequencing, they found larval bacterial communities persistently dominated by Enterobacteriaceae across developmental stages (> 85\% in relative abundance) [41]. However, another group reported a significant succession pattern in larval shrimp microbiota with host development [42]. These previous studies with relatively low sampling frequency have yielded controversial results, indicating that an investigation at a fine temporal scale into larval shrimp microbiota in aquaculture practice is needed.

Unveiling the assembly mechanism of shrimp microbiota can help resolve the debate on whether we could improve the success rate of shrimp culture via manipulating their microbiota. Microbial community assembly is generally governed by two categories of ecological processes: deterministic and stochastic. Deterministic processes include abiotic selection and biological interaction, while stochastic processes (also known as neutral processes) include dispersal-related processes and ecological drift $[43,44]$. Recently, neutral models have been used to disentangle the assembly processes of each species in host microbial communities $[17,43,45,46]$. This model assumes that individuals in a local community could be randomly lost and then replaced by other members in the community and/or supplemented from metacommunity (species pool) via dispersal [46, 47]. The neutral model infers assembly processes by fitting 
the relationship between the occurrence frequency of species in the local communities and their abundance in the metacommunity $[46,48]$. The species with occurrence frequency deviated from that predicted by the model are considered to be selected for or against by the local community, or have a different ability to disperse compared with the neutrally distributed species $[43,46]$. Using this approach, Burns et al. found that the contribution of neutral processes to the assembly of zebrafish intestinal bacteria declined with host development [46], while the importance of neutral processes in shaping intestinal bacterial communities increases with the age of shrimp (from postlarvae to adult) in culture practice, but declined with disease outbreak [17]. However, little is known about the dynamics and taxonomic dependency of assembly processes of bacteria in larval shrimp.

In this study, we used 16S rRNA gene amplicon sequencing to investigate the succession and assembly processes of L. vannamei larval bacterial community in a realistic aquaculture practice with sufficient biological replicates. A high-frequency sampling strategy was applied to collect shrimp larvae (from the fertilized eggs of a pair of parents) and rearing water samples across nauplius, zoea I, zoea II, zoea III, mysis, and early postlarvae stages lasting for 15 days (The sampling details are shown in Additional file 2: Figure S1). Using multivariate analyses, the neutral model, and functional prediction (with PICRUSt2 [Phylogenetic Investigation of Communities by Reconstruction of Observed States] [49]), we aimed to reveal the following: (1) the dynamics of $\alpha$ diversity, composition, and predicted functional potentials of larval shrimp bacterial community with host development, (2) the taxonomic and phylogenetic succession pattern of larval bacterial community, (3) the dynamics and taxonomic dependency in assembly processes of larval shrimp bacteria across developmental stages, and (4) to what extent the rearing water bacterioplankton can influence the assembly of larval shrimp bacteria.

\section{Results}

\section{Alpha-diversity of bacterial community}

The bacterial $\alpha$-diversity indices of shrimp larvae and rearing water showed dramatic variability with host development. Bacterial $\alpha$-diversity and evenness of larvae were at a high level at nauplius stage, then decreased at zoea I stage, and finally reverted to the initial level at early postlarvae stage (Fig. 1, Additional file 2: Figure S2). Species richness and phylogenetic diversity decreased sharply from nauplius to zoea I $(P<0.05)$, and then remained stable until mysis stage, while Shannon and Pielou's evenness indices showed a declining trend from nauplius to mysis (Additional file 2: Figure S2). At the finer time-scale, bacterial $\alpha$-diversity showed certain fluctuation even in a short period of time, especially during the stages nauplius and early postlarvae (Fig. 1).

Species richness and phylogenetic diversity of bacterioplankton in the rearing water showed somewhat increasing trend with host development, but relatively stable and significantly lower compared with those of larvae at the stages nauplius, zoea I-II, and early postlarvae (Additional file 2: Figure S2). The Shannon and evenness indices of larval bacterial community were significantly higher than that of bacterioplankton at the stages nauplius and zoea I-II, but showed an opposite pattern at the stages zoea III and mysis. Finally, $\alpha$-diversity of bacterioplankton reached the highest level at early postlarvae stage.

\section{Dynamics of dominant bacterial taxa in shrimp larvae}

The bacterial communities of naupliar shrimps mainly dominated by $\gamma$-Proteobacteria (43.6\% in average relative abundance), Bacteroidetes (20.0\%), $\alpha$-Proteobacteria (15.7\%), and Firmicutes (8.5\%) (Fig. 2). At zoea stage, the dominant groups shifted to $\alpha$-Proteobacteria (72.4\%, mainly Rhodobacteraceae, 69.8\%) and Bacteroidetes (20.8\%, including Cyclobacteriaceae, 12.8\%), while the relative abundance of $\alpha$-Proteobacteria further increased to the extreme dominance (86.2\%, mainly Rhodobacteraceae, $84.9 \%)$ at mysis stage. However, the average relative abundance of Rhodobacteraceae decreased to $58.3 \%$ at early postlarvae stage, while Firmicutes (15.8\%), $\gamma$-Proteobacteria (9.9\%), and Chloroflexi (3.6\%) were enriched. Overall, the composition of dominant bacterial groups (at the phylum or family level) at the stages nauplius and postlarvae were more complex than other stages. Linear discriminant analysis effect size (LEfSe) showed the discriminatory taxa of larval shrimp microbiota at different stages, with the class Sphingobacteria (mainly the family Saprospiraceae), the class Flavobacteria (including the genera Pseudofulvibacter, Nonlabens, and Crocinitomix), Actinobacteria (including the genera Pseudonocardia and Gordonia), and $\gamma$-Proteobacteria (including the genera Vibrio, Reinekea, and Pseudoalteromonas) more abundant at nauplius stage; the class Cytophagia (including the genus Algoriphagus) and two Rhodobacteraceae genera Roseovarius and Donghicola at zoea stage; the genus Ilumatobacter, the family Rhodobacteraceae, and Planctomycetes (including the genus Rhodopirellula) at mysis stage; Firmicutes (including the order Clostridiales and the genera Lactobacillus and Bacillus), the genus Pseudomonas, the family Enterobacteriaceae, and a Rhodobacteraceae genus Ruegeria at early postlarvae stage (Additional file 2: Figure S3).

The heatmap shows the succession pattern of dominant bacterial OTUs (operational taxonomic units) of shrimp larvae, and $89.1 \%$ of samples could be classified into four clusters according to the developmental stage: cluster I (nauplius), cluster II 


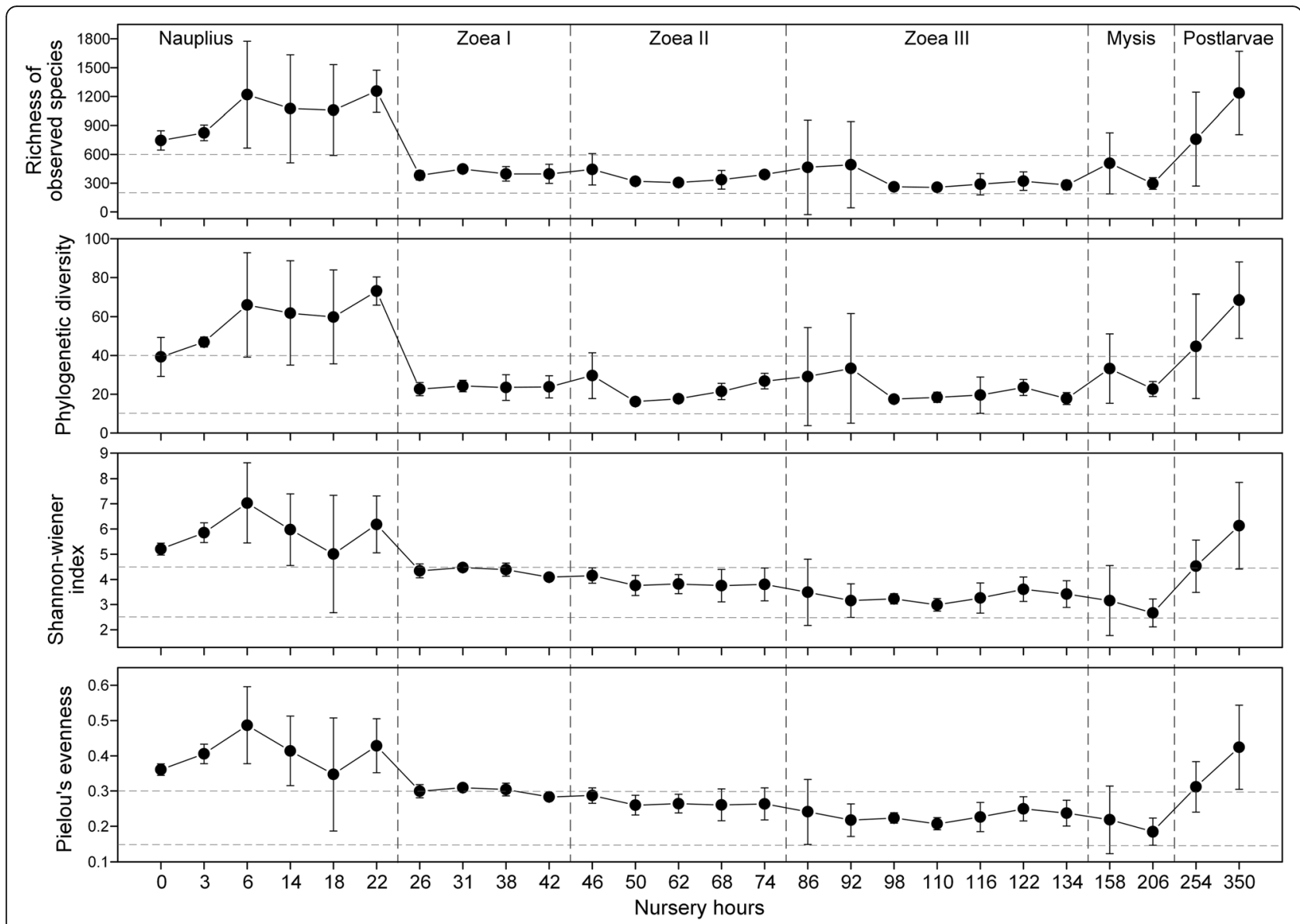

Fig. 1 Fine-scale temporal dynamics of a-diversity and evenness indices of larval shrimp bacterial communities. Data present means \pm standard deviation

(zoea I and II), cluster III (zoea III), cluster IV (mysis and postlarvae) (Fig. 3). It is worth noting that the composition of dominant OTUs were complex before the mouth opening of larvae. However, after the mouth opening, the composition of dominant OTUs tended to be simple, when the OTU turnover was largely represented by switching among Rhodobacteraceae taxa. Specifically, 10 Rhodobacteraceae OTUs were predominated in cluster II, but only 2 of them remained predominant in cluster III with other two emerging ones, and then a subset of dominant Rhodobacteraceae OTUs in the 2 previous stages were present in cluster IV.

\section{Taxonomic and phylogenetic turnover of bacterial community with host development}

In general, bacterial community compositions of shrimp larvae and rearing water were both clustered according to developmental stages (Fig. 4, Additional file 1: Table S1). The taxonomic composition of bacterial community in larvae and water showed distinct successional trajectories, while the phylogenetic turnover trajectories of two communities overlapped to some extent during the sub-stages of zoea (Fig. 4a, b). As evidenced by One-way analysis of similarity (ANOSIM), the compositions of larval and water bacterial communities were significantly different at any stages (all $P<0.01$, Additional file 1: Table S2). Furthermore, the succession of larval bacterial community taxonomically and phylogenetically fitted the time-decay model (all $P<0.001$ ) with a much greater rate of OTU turnover $\left(w=-0.573, R^{2}\right.$ $=0.337)$ compared with phylogenetic turnover rate $(w=-$ $0.047, R^{2}=0.069$ ) (Fig. 4c, d).

\section{The relationship between larval and water bacterial communities}

We observed overall low taxonomic similarity but high phylogenetic similarity between larval and water bacterial communities (Additional file 2: Figure S4). Before the mouth opening (nauplius), the similarity between larval and water communities was low (19.0\% in average taxonomic similarity and $65.0 \%$ in phylogenetic similarity), and rose to the highest level $(45.2 \%$ and $83.1 \%)$ after the mouth opening (zoea I). But it decreased to the initial level at later stages (mysis and early postlarvae). In addition, we found that larval bacterial communities at 

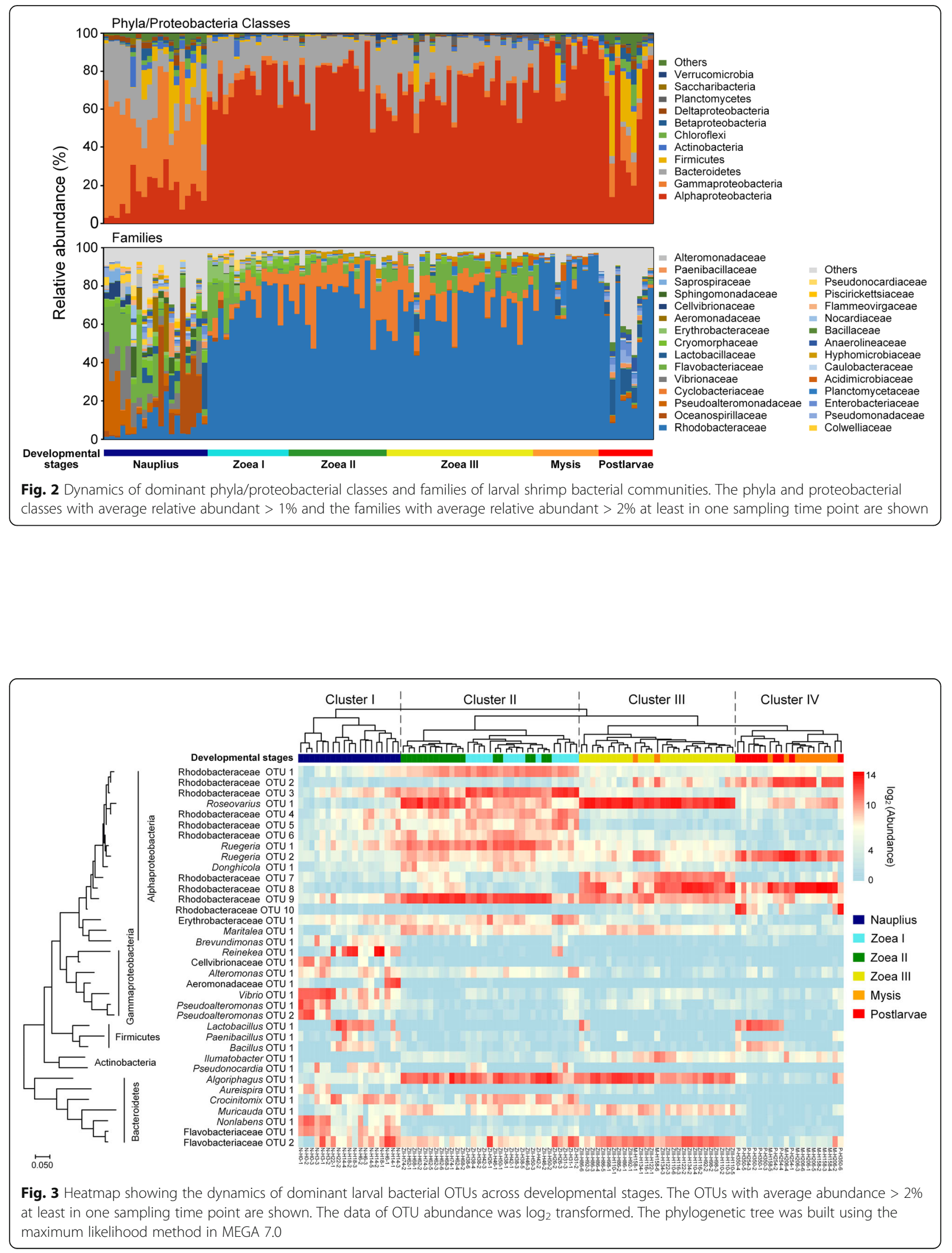

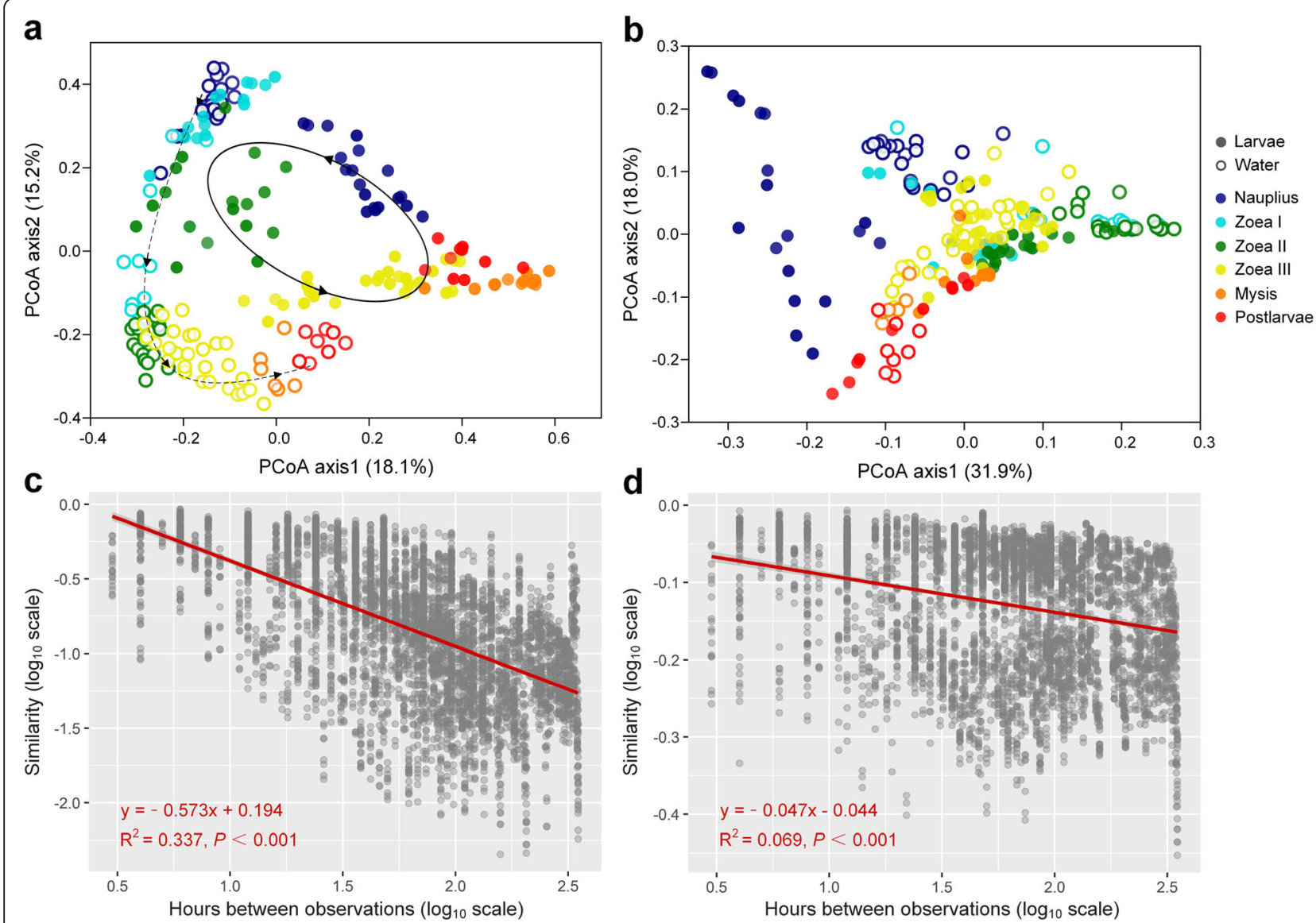

Fig. 4 Taxonomic and phylogenetic turnover of larval and water bacterial communities with host development. Principal coordinate analysis (PCoA) visualizing compositional variations of larval and water bacterial communities across developmental stages based on Bray-Curtis dissimilarity (a) and weighted UniFrac distance (b). Time-decay in similarity between larval bacterial communities based on Bray-Curtis similarity (c) and phylogenetic similarity based on UniFrac distance (1 - weighted UniFrac distance) (d). The data of similarity values and hours between observations were shown as $\log _{10}$ transformed

the stages zoea I-II and mysis showed higher similarities and/or more shared OTUs with the water bacterial communities from the previous stage compared with that at the same stage $(P<0.01$, Additional file 2: Figure S5).

\section{Fit of the neutral model for larval shrimp bacteria}

Before the mouth opening (nauplius) and at the later stages (mysis and early postlarvae), the OTUs shared by larval and water bacterial communities accounted for only 9.1 11.4\% of the total OTUs of two communities, but after the mouth opening, the proportion of shared OTUs reached to 19.4 23.3\% during zoea sub-stages (Fig. 5a). When assuming water bacteria as the source community, the occurrence of the shared OTUs in larval bacterial communities only fitted the neutral model at three sub-stages of zoea $\left(R^{2}=\right.$ $0.200 \sim 0.364$ ), indicating that bacterioplankton served as one of the important sources of larval bacterial communities during the zoea stage. In this period, the cumulative relative abundance of the neutrally distributed OTUs (zoea I 93.4\%, zoea II 74.3\%, zoea III 33.0\%) and the estimated migration rate ( $m$, zoea I 0.309 , zoea II 0.226 , zoea III 0.042 ) both gradually decreased (Fig. 5a), and the taxonomic distribution of the three categories OTUs in the neutral model also varied with host development (Fig. 5b). The neutrally distributed OTUs were predominated by $\alpha$ Proteobacteria (mainly Rhodobacteraceae) and Bacteroidetes, and the relative abundance of $\alpha$-Proteobacteria declined with host development (from 70.2 to 9.3\%). The OTUs above prediction were mainly from $\alpha$-Proteobacteria (mainly Rhodobacteraceae) and $\gamma$-Proteobacteria, and the relative abundance of $\alpha$-Proteobacteria dramatically increased from $2.5 \%$ to $60.5 \%$ with host development.

When assuming larval bacterial metacommunity as the source community, the goodness of fit of the neutral model was largely improved $\left(R^{2}=0.505 \sim 0.822\right)$ compared with that when assuming bacterioplankton as the source across all stages (Fig. 6), suggesting that exchange of bacteria among larval individuals was a more important source of larval bacterial communities. The cumulative relative abundance and taxonomic distribution of three 


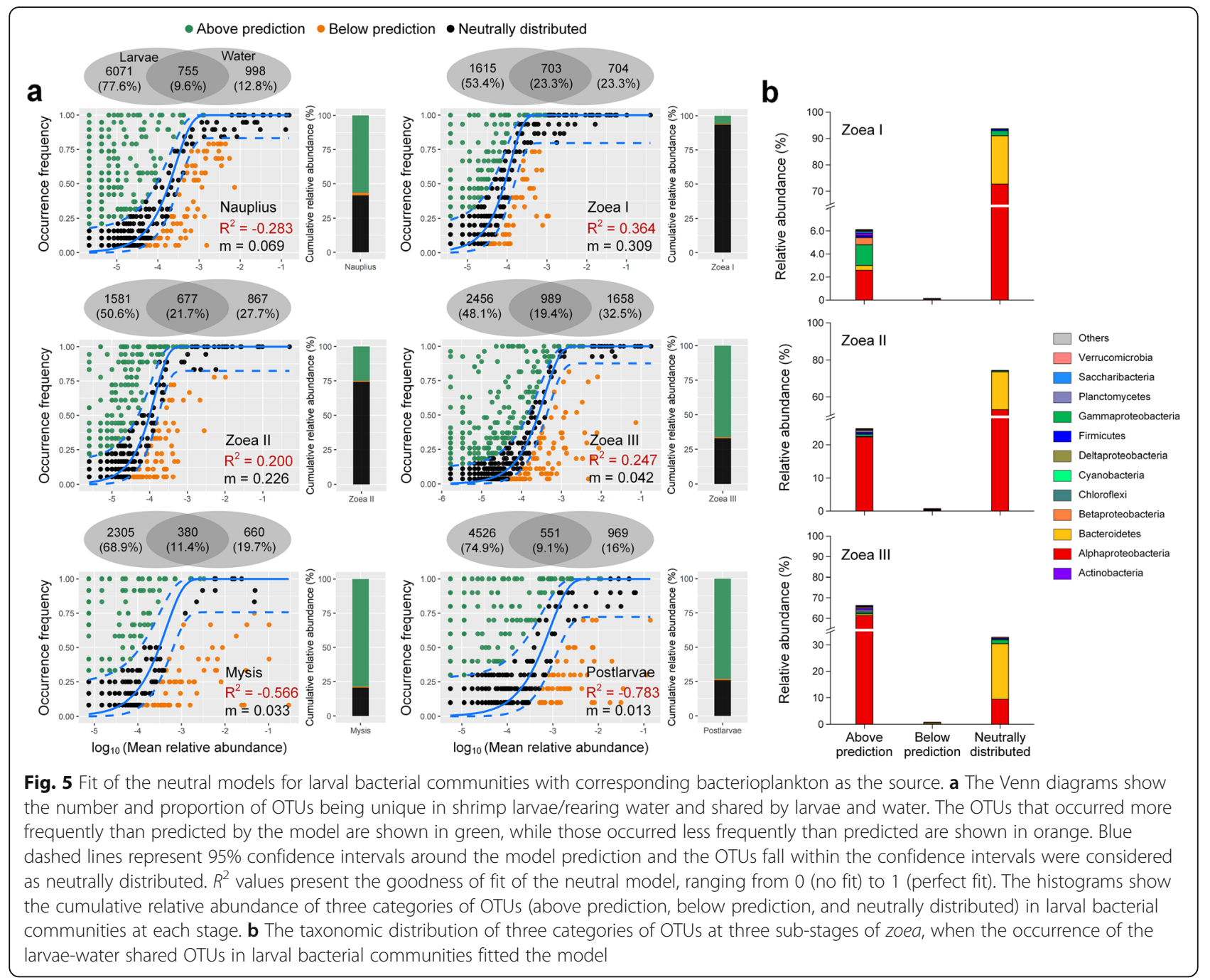

categories of OTUs in the neutral model varied with host development, especially between pre- and post-mouth opening stages (Fig. 6a). The relative abundance of the neutrally distributed OTUs was $69.6 \%$ before the mouth opening (nauplius), and sharply increased to $95.9 \%$ afterwards (zoea I) with more than $94 \%$ of OTUs neutrally distributed at each stage. The neutrally distributed OTUs were dominated by $\gamma$-Proteobacteria $(31.5 \%$ in average relative abundance), Bacteroidetes (16.9\%), and $\alpha$-Proteobacteria $(11.4 \%)$ at nauplius stage. After the mouth opening, the neutrally distributed $\gamma$-proteobacterial OTUs showed a rapid decrease in relative abundance (zoea I $3.0 \%$, zoea II $1.0 \%$, zoea III 1.5\%) and were soon replaced by $\alpha$-proteobacterial OTUs (zoea I $72.5 \%$, zoea II $74.1 \%$, zoea III 69.3\%). The relative abundance of neutrally distributed $\alpha$-proteobacterial OTUs further increased to $84.6 \%$ at mysis stage, followed by a decrease in $\alpha$-Proteobacteria (53.7\%) and an increase in Firmicutes (15.2\%) at early postlarvae stage. The cumulative relative abundance of the OTUs above prediction was overall low $(<2.4 \%)$ across developmental stages, with little changes in the taxonomic distribution. The cumulative relative abundance of the OTUs below prediction before the mouth opening was $28.3 \%$, but dramatically decreased to $3.5 \%$ afterwards. At any stages, the assembly of larval bacteria was dominantly governed by neutral processes, and the neutral model performed better than the binomial distribution model (according to Akaike Information Criterion, AIC) (Fig. 6b), suggesting that, except dispersal, ecological drift and dispersal limitation also contributed. In addition, the estimated migration rate $(m)$ peaked at the stages zoea I-II, and then decreased at the stages mysis and postlarvae (Fig. 6b), suggesting enhanced dispersal of bacteria among larval individuals right after mouth opening and a stronger dispersal limitation in the later stages.

\section{Predicted functional profiles of larval shrimp bacterial community}

Large differences in functional profiles of larval shrimp bacterial community between pre- and post-mouth opening 


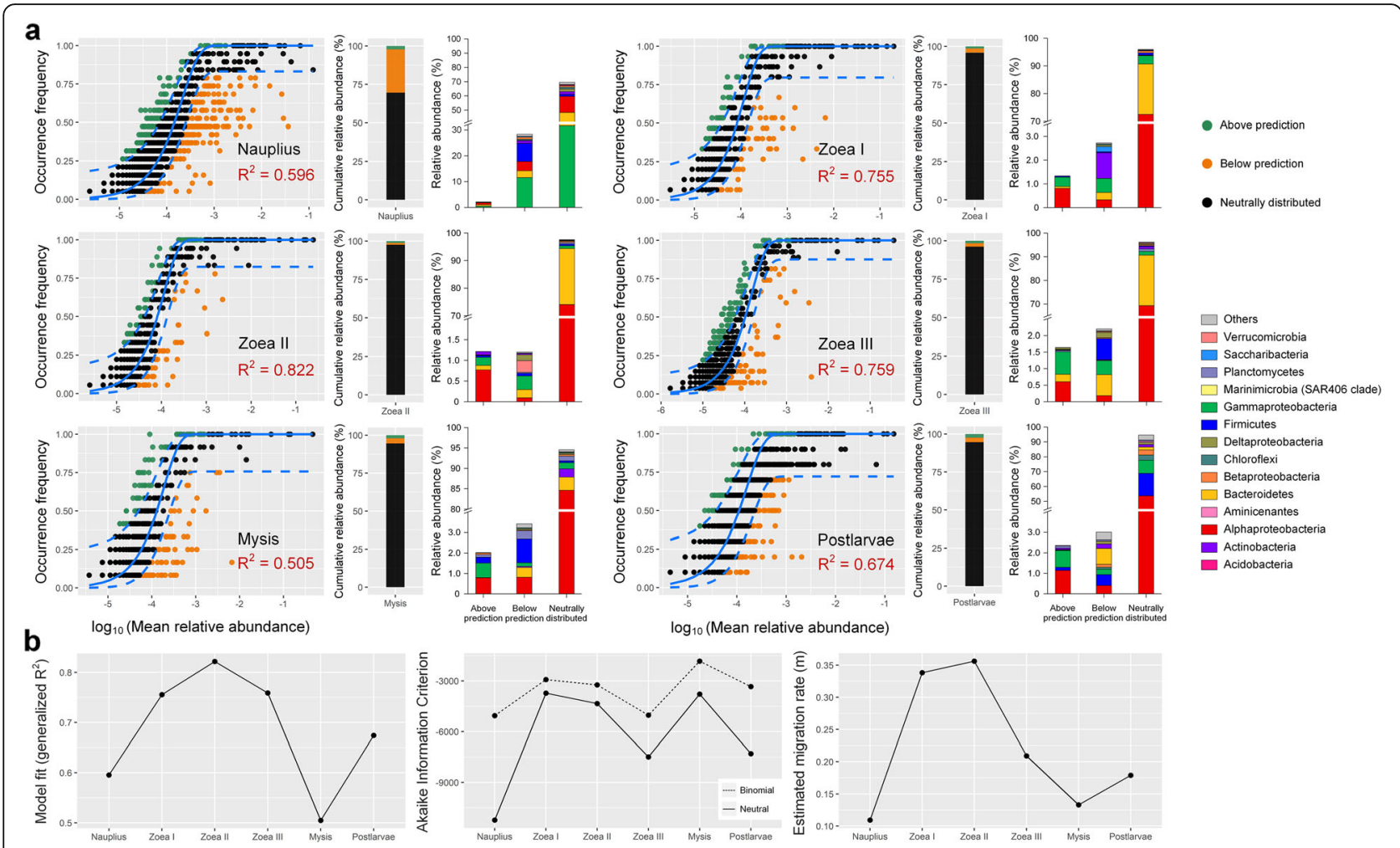

Fig. 6 Fit of the neutral models for larval bacterial communities with larval matecommunity as the source. a The OTUs that occurred more frequently than predicted by the model are shown in green, while those occurred less frequently than predicted are shown in orange. Blue dashed lines represent 95\% confidence intervals around the model prediction and the OTUs fall within the confidence intervals were considered as neutrally distributed. $R^{2}$ values present the goodness of fit of the neutral model, ranging from 0 (no fit) to 1 (perfect fit). The cumulative relative abundance and taxonomic distribution of three categories of OTUs (above prediction, below prediction, neutrally distributed) in larval bacterial communities at each stage are shown. $\mathbf{b}$ The dynamics of $R^{2}$ value of the neutral model, Akaike Information Criterion comparing the fit of the neutral model and the binomial distribution model, and the estimated migration rate $(\mathrm{m})$ of larval bacterial communities across developmental stages

stages was predicted by PICRUSt2 (Additional file 2: Figure S6a). In general, functional potentials relevant with genetic information processing were enriched in naupliar shrimps compared with larvae at post-mouth opening stages, while many metabolism-relevant potentials (such as biosynthesis of other secondary metabolites and the metabolism of amino acids; carbohydrate; lipid; cofactors and vitamins; and terpenoids and polyketides) were enriched in larvae after the mouth opening. However, some metabolismrelevant potentials somewhat showed a decreasing trend at early postlarvae stage. As the predominant bacterial group at the stages zoea and mysis, the family Rhodobacteraceae was predicted to be the major contributor to functional potentials (including metabolism) of larval shrimp bacterial community (Additional file 2: Figure S6b).

\section{Discussion}

The U-shaped pattern in larval bacterial a-diversity with host development

The $\alpha$-diversity of larval shrimp bacteria varied with host development, corresponding to previous reports about larvae of aquatic animals such as cod (Gadus morhua) [50], gibel carp (Carassius auratus gibelio) [51], southern catfish (Silurus meridionalis) [52], and zebrafish (Danio rerio) [53]. In this study, larval bacterial $\alpha$-diversity indices all showed a U-shaped pattern with host development. As the larvae are too small to obtain their intestines, the larval microbiota should be mainly derived from the intestinal tract and the fraction attached to the epidermis. At nauplius stage, with the release of yolk nutrients and the enlargement of epidermis area, the larval bacterial community could be mainly originated from fertilized eggs (the inheritance of the parents and initial hatching environment) and the epidermis attachment, thus maintaining at a relatively high diversity. When the larvae started eating at zoea I stage, their intestinal microbiota began to form, while the larvae molted, imposing the reassembly of larval bacterial community. These changes could lead to the dominance of intestinal bacteria in larval microbiota and thus decrease $\alpha$-diversity. The $\alpha$-diversity of larval bacteria was relatively stable across three sub-stages of zoea (with a slight 
declining trend in Shannon index). During this period, the host development (especially the intestinal tract) was largely immature, resulting in low niche diversity that can be provided [51, 54]. This could be a key explanation for the low $\alpha$-diversity of larval bacteria at that time. In addition, the species richness and phylogenetic diversity of the zoeal bacterial community were very close to that of bacterioplankton in rearing water (Additional file 2: Figure S2). A previous study found that the intestinal microbiota of coho salmon (Oncorhynchus kisutch) after first feeding was mainly from water and egg epidermis [55]. We also found that water was an important source of larval bacteria at zoea sub-stages (see the Discussion below). At early postlarvae stage, $\alpha$-diversity of larval bacteria bounced back to a similar level at nauplius stage, likely due to the more diverse niches provided by the intestinal tract tending to be mature and complex [51,54].

Shrimp larvae (especially at zoea sub-stages) often have weak immune systems and are vulnerable to zoeaII syndrome, which can lead to high mortality $[56,57]$. Some studies have shown that the diversity of animal intestinal microbiota is closely related to their functional integrity and stability $[58,59]$. Although a point of view has suggested that the higher microbial diversity does not necessarily correspond to a more stable and healthy ecosystem [60], high diversity is often considered to hold capability of maintaining the stability and ecological function of microbial community, thus being an important indicator of host health status [61, 62]. A previous work has found that the intestinal bacterial $\alpha$-diversity of L. vannamei with normal growth rates was higher than that of retarded or overgrown shrimps [12]. Moreover, the higher bacterial $\alpha$-diversity was also observed in the intestinal tract of healthy individuals and the coldresistant strain of $L$. vannamei relative to that of diseased individuals and the cold-vulnerable strain, respectively $[13,16,17,63]$. These studies suggest that high bacterial diversity could be a positive signal for maintaining the growth, health, and stress-resistance of shrimps. To some extent, the valley of larval bacterial $\alpha$-diversity during the zoea stage confirms a common empirical view in aquaculture industry that the zoeal shrimps were most vulnerable to the stress and disease in the complete larval developmental cycle $[56,57]$ on a perspective of microbial ecology, further suggesting that zoea is a key stage for ensuring the success of larval nursery.

\section{Larval bacterial community composition varied with host development}

The high-frequency sampling strategy facilitated the unveiling of highly dynamic pattern of larval bacterial communities. The taxonomic and phylogenetic compositions of larval bacteria both showed stage-dependent patterns, even between the sub-stages of zoea. This is consistent with the pattern observed in the intestinal bacterial community of fish larvae [50, 52, 53]. In addition, we found distinct compositions and successional trajectories between larval and water bacterial communities. Similar results were often reported in juvenile and adult shrimps (L. vannamei and Macrobrachium nipponense) $[17,23,28,29,38,39]$. The shrimp larvae with immature digestive system could partially rely on the assistance of bacteria for food digestion and nutrient metabolisms [64], which is corresponding to the enriched metabolic potentials of multiple organic matters in larval shrimp microbiota after the mouth opening (especially at the stages zoea and mysis), as predicted by PICRUSt2. Thus, the high variability of bacterial community composition might be due to the host's recruitment of different functional groups for physiological needs [65]. As the morphological and physiological properties of intestinal tract change with host development, the initial "winners" will be reorganized to form a stage-specific bacterial community [66].

Zheng et al. found that Enterobacteriaceae were persistently predominant ( $>85 \%$ in relative abundance) in larval bacterial communities of L. vannamei across developmental stages, though Rhodobacteraceae were ubiquitous at all stages (second abundant in many of them) [41]. These findings are contrasting to our result, that is, Enterobacteriaceae kept at low relative abundance $(0.03 \sim 2.7 \%)$, while Rhodobacteraceae maintained the overwhelming dominance after the mouth opening. Unlike the simple composition of dominant bacterial families in Zheng et al. [41], we found more dynamic changes in bacterial community as represented by dramatic fluctuation in relative abundance of Rhodobacteraceae, Cyclobacteriaceae, and Flavobacteriaceae (Fig. 2). Xue et al. have suggested that the choice of DNA extraction kits may result in DNA recovery biases, thus influencing the characterization of larval bacterial community of L. vannamei [42]. However, they found $\alpha$-Proteobacteria (Rhodobacteraceae), $\gamma$-Proteobacteria, Bacteroidetes (Flavobacteriaceae), and Firmicutes as the main dominant groups of larval bacterial communities and pronounced succession in community composition, regardless of DNA extraction kits. This fits the general view of our work. Furthermore, they also found the dominance of Rhodobacteraceae when using the Stool DNA Kit (Omega, USA), but showing an opposite dynamic pattern ( $>80 \%$ in relative abundance at nauplius stage, followed by a decrease to $<30 \%$ in the middle and late stages) compare with that in our study. This suggests that the differences in environmental conditions of nursery systems may also lead to distinct patterns in larval microbiota dynamics. Future efforts are needed to reveal the impact of local environmental conditions on the succession of larval shrimp bacterial communities.

Many studies have found that host development [30, 53, 67] and diet $[35,51]$ largely shape the intestinal microbiome of aquatic animals. In this study, the shifts of physiological state, 
nutritional intake mode, and microbial source between preand post-mouth opening stages likely led to dramatic differences in larval bacterial communities. It is worth noting that, after the mouth opening, the OTU composition of bacterial community rapidly varied, but the turnover of dominant OTUs mainly occurred within the family Rhodobacteraceae (Fig. 3). Furthermore, the time-decay model showed that the OTU turnover rate of larval bacterial community was much higher than phylogenetic turnover rate. These results suggest that the taxonomic turnover of larval bacteria was mainly driven by temporal switching among closely related taxa. Many studies have found Rhodobacteraceae persistently dominant in the intestinal tract of $L$. vannamei across juvenile to adult stages (ranging from 6 to $50 \%$ in average relative abundance) $[13,17,23,28,34]$. Therefore, the family Rhodobacteraceae is likely a core group of intestinal microbiota of $L$. vannamei. Rhodobacteraceae are heterotrophic bacteria with extremely high diversity and versatility in organic matter degradation, and widely distributed across various marine ecosystems [68-70]. Most Rhodobacteraceae taxa are able to synthesize vitamin $B_{12}$, which is a dietary essential for shrimps [71]. Moreover, functional prediction showed that the family Rhodobacteraceae largely contributed to the potentials in biosynthesis and the metabolism of multiple organic matters after the mouth opening of larvae, indicating that they may participate in the metabolism of organic matters in the digestive tract of larvae and/or provide essential nutrients for host growth. The relative abundance of Rhodobacteraceae in the intestinal bacterial community of healthy L. vannamei individuals is often higher than that of diseased ones, and shows an antagonistic relationship with potential pathogens such as Vibrio $[36,72,73]$. One proven example is that strains of the species Ruegeria sp. and Phaeobacter sp. (both affiliated to Rhodobacteraceae) can produce tropodithietic acid (TDA) to inhibit Vibrio anguillarum, thus holding probiotic potential [74-76]. In addition, Xiong et al. found that the relative abundance of Rhodobacteraceae in the intestinal bacterial community of $L$. vannamei individuals with normal growth rate was higher than that of retarded or overgrown ones [12]. The higher relative abundance of Rhodobacteraceae was also observed in the intestinal tract of cold-resistant strain of $L$. vannamei relative to coldvulnerable strain [13]. Collectively, we speculate that the dramatic enrichment of Rhodobacteraceae (including some Ruegeria taxa) after the mouth opening of larvae may play a positive role in promoting digestion, providing nutrients, and inhibiting pathogens. Furthermore, the temporal switching among Rhodobacteraceae taxa suggests distinct assemblages of Rhodobacteraceae taxa could be recruited for maintaining certain functions such as the metabolism of different organic matters derived from the partially modified feeds at different stages. Thus, the family Rhodobacteraceae might be a potential source of probiotics for larval shrimp nursery. To test these hypotheses, using metagenomics and metatranscriptomics to study the metabolic potentials of distinct Rhodobacteraceae taxa and how they functioning at various developmental stages of shrimp larvae should be considered as an important future direction.

\section{Neutral processes dominated the assembly of larval bacteria}

According to the fitting of the neutral model, we found that larval bacterial communities mainly sourced from the larval metacommunity, while water bacterioplankton community only had certain contribution at zoea substages. In general, the neutral processes dominantly governed the assembly of larval bacteria, corresponding to the findings in zebrafish larvae [53]. These results suggest that the assembly of larval bacteria overall depends on the exchanges among individuals, probably via crossfeeding of feces and/or bioflocs [24, 77, 78]. The influence of host morphology on the assembly processes of microbiota has been demonstrated in many kinds of fishes $[53,65]$. When larval shrimps are undergoing continuous metamorphic development with frequent molting and feed replacement, their bacterial communities are also undergoing frequent reassembly. Coupled with their physiological immaturity, the relative abundance of OTUs above the neutral prediction was low, suggesting the overall weak host selection. It is worth noting that the relative abundance of OTUs below the prediction was the highest before the mouth opening (nauplius), when the migration rate $(m)$ was the lowest (Fig. 6). This suggests that dispersal limitation was strong at this stage, because bacteria could not be exchanged among larval individual via feeding. The substantial improvement of the neutral model's fitting goodness over the binomial distribution model at this stage further confirmed the importance of dispersal limitation. After the mouth opening, especially at the stages zoea I-II, the fitness of the neutral model $\left(R^{2}\right)$ rapidly increased, the migration rate rose to the highest level, and the gap of fitness between the two models decreased, suggesting that dispersal process dominated the assembly of larval bacteria. In the subsequent stages, the migration rate and relative abundance of neutrally distributed OTUs showed a declining trend, probably because the improvement in matureness of shrimp larvae led to the enhancement of host selection on microbiota. In addition, the compositions of OTUs neutrally distributed or deviated from neutral prediction between pre- and post-mouth opening stages were dramatically different. These results reveal the remarkable succession pattern and the dynamics in assembly processes of larval bacterial communities, emphasizing the importance of the mouth opening stage of larval shrimp from the ecological perspective. 
Many studies have found that the initial establishment of host microbiome can be affected by the surrounding environment [38, 79, 80]. We also found rearing water as a source of larval bacterial community at three substages of zoea, which can be considered as the beginning of establishment of larval intestinal microbiota (Fig. 5). At the zoea stage, the proportion of shared OTUs and composition similarity between larval and water bacterial communities reached the highest level, as was the estimated migration rate of water bacteria to the larval community, suggesting that larval and water bacterial communities were most associated in this period. Therefore, zoea may be a critical stage for the regulation of larval microbiota through manipulating the microbial community of rearing water. On the other hand, it is particularly important to ensure the microbial safety of rearing water (such as prevention of pathogenic bacteria) after the mouth opening of larvae. In addition, compared with the water bacterial community at the same stage, the larval bacterial communities of zoea I-II and mysis all showed a stronger association with the water community from the previous stage (Additional file 2: Figure S5). Similar time lag in colonization of environmental bacteria into zebrafish has been observed [53]. This suggests that the regulation of larval microbiota by microbial management of rearing water in aquaculture practice should be launched before the mouth opening of shrimp larvae.

Taken bacterioplankton as the source for the neutral model fitting, the relative abundance of the neutrally distributed OTUs and the migration rate gradually decreased during zoea sub-stages, indicating that the dominant process governing the colonization of bacterioplankton into larval communities shifted from dispersal to host selection. The relative abundance of OTUs above prediction gradually increased during zoea sub-stages (zoea I 6.1\%; zoea II 24.9\%; zoea III 66.3\%) (Fig. 5), especially Rhodobacteraceae OTUs (zoea I 2.0\%, zoea II 22.3\%, zoea III 61.1\%), suggesting that Rhodobacteraceae taxa in the rearing water can adapt to the internal environment of larvae, and be positively selected by the host. Knowing which bacteria are selected for and have the ability to persist in a host is vital when screening probiotic candidates [81]. The above prediction taxa may be good candidates for potential probiotics because they have a greater chance for colonization [17]. Therefore, targeted isolation of Rhodobacteraceae taxa positively selected by larval shrimp and further study on their functions and interaction with the host will help to discover novel probiotics suitable for larval shrimp nursery.

\section{Conclusions}

To the best of our knowledge, this study is the first systematic characterization on succession patterns and assembly processes of larval shrimp bacterial community at a fine temporal scale in aquaculture practice. The diversity and composition of larval bacterial community dynamically varied with host development, with the Ushaped pattern of $\alpha$-diversity, the overwhelmingdominance of Rhodobacteraceae since zoea I stage (the mouth opening of larvae), and the OTU turnover driven by temporal switching among closely related taxa as the major signatures of the succession patterns. Our results based on the neutral model revealed that the major assembly process of larval bacteria was dispersal among individuals coupled with ecological drift, while bacterioplankton also contributed to some extent during the zoea stage. Given the positive host selection for Rhodobacteraceae taxa from the rearing water during the zoea stage and its persistent dominance and large potential contribution to the metabolism of organic matters after the mouth opening of larvae, we suggest that Rhodobacteraceae could be crucial in the growth of shrimp larvae and thus be a potential source of probiotic candidates for larval nursery. Collectively, the succession patterns and assembly mechanism of larval shrimp bacteria we revealed here highlighted the importance of the mouth opening stage from the perspective of microbial ecology, indicating the possibility and timing of microbial management of the rearing water for larval microbiota regulation and pathogen prevention in larval shrimp nursery practice. One limitation of this work is that the dynamics of some important water parameters such as nutrients was not monitored corresponding to the high-frequency sampling scheme, due to the heavy workload. According to the baseline of larval bacterial community succession we revealed, future efforts should be made based on the reduced sampling frequency and more comprehensive environmental profiles for understanding the impact of water quality and feed ingredients on the succession and assembly of larval shrimp bacterial community.

\section{Methods \\ Experimental design and sample collection}

The larval shrimp nursery ponds were located in Wenchang, Hainan Province, China $\left(20.148^{\circ} \mathrm{N}, 110.687^{\circ} \mathrm{E}\right)$. Six standardized ponds $(4 \mathrm{~m} \times 5 \mathrm{~m} \times 1.3 \mathrm{~m})$ in a larval nursery room were selected for monitoring and were maintained by the uniform management including the input and pre-treatment of seawater (before introducing larvae) and the source of eggs. This study used eggs from the same pair of parents to minimize genetic divergence and inter-individual differences. During the nursery, the rearing water was constantly aerated and maintained under the following conditions: temperature $30-32{ }^{\circ} \mathrm{C}, \mathrm{pH} 8.0-$ 8.3, salinity 30-33 PSU, and dissolved oxygen $5-8 \mathrm{mg} / \mathrm{L}$. The concentration of inorganic nitrogen was monitored at the beginning of the nursery process, with nitrite nitrogen $<0.005 \mathrm{mg} / \mathrm{L}$ and ammonia nitrogen < $0.01 \mathrm{mg} / \mathrm{L}$. The commercial shrimp flakes were used 
to feed larvae at all stages after the mouth opening (6 times/day). At the stages zoea I-II, live microalgae Chaetoceros sp. and Thalassiosira sp. were also used (3-4 times/day). At the stages zoea III and mysis, frozen brine shrimps (Artemia) were used (3 times/day), and then were replaced by live brine shrimps at the early postlarvae stage. The initial density of larval shrimps was 3.5 million nauplii each pond with $\sim 13,000 \mathrm{~L}$ of water. Both larvae and rearing water samples were collected across nauplius, zoea I, zoea II, zoea III, mysis, and early postlarvae stages lasting for 15 days ( $350 \mathrm{~h}$ exactly). The developmental stages of larvae were confirmed by microscopy. The strategy and timeline of the sampling are shown in Additional file 2: Figure S1 in detail. Briefly, using a dense-to-sparse sampling strategy from early to later developmental stages, 26 sampling time points were set to collect both shrimp larvae and water samples, except at the 31st, 206th, and 254th hour when only the larvae samples were collected. We randomly picked three ponds for all-time sampling, and the other three ponds were sampled at one time point of each stage (except two time points at zoea III, mysis, and early postlarvae stages). Shrimp larvae were soaked and washed for 10-15 s with sterilized water to remove the adsorbed rearing water, and then were transferred into sterilized and enzyme-free centrifuge tubes, followed by centrifugation at $700 \mathrm{rpm}$ for $1 \mathrm{~min}$, to obtain larval precipitates (about $0.8 \mathrm{~g} /$ pond). At the same time, rearing water samples were collected ( $3 \mathrm{~L} /$ pond) and then filtered onto a $0.2-\mu \mathrm{m}$ polycarbonate membrane (Millipore, USA) after the pre-filtered with $100-\mu \mathrm{m}$ sterilized nylon mesh. A total of 103 shrimp larvae samples and 92 water samples were collected and stored at $-80{ }^{\circ} \mathrm{C}$ until DNA extraction.

\section{DNA extraction, 16S rRNA gene amplification, and Illumina sequencing}

DNA on polycarbonate membrane was extracted using the Power Soil ${ }^{\circ}$ DNA Kit (MOBIO, USA). Total DNA of shrimp larvae was extracted using the QIAamp ${ }^{\circ}$ DNA Stool Mini Kit (Qiagen, Germany). The V4 region of $16 \mathrm{~S}$ rRNA genes was amplified using primers 515F-Y (5'GTGYCAGCMGCCGCGGTAA-3') and 806R-B (5'GGACTACNVGGGTWTCTAAT-3') with dual barcodes [82, 83]. To minimize reaction-level PCR bias, 10 ng purified DNA template from each sample was amplified in triplicate with a $20-\mu \mathrm{L}$ reaction system under the following conditions: initial denaturation at $95{ }^{\circ} \mathrm{C}$ for 3 min; then 27 cycles of denaturation at $95{ }^{\circ} \mathrm{C}$ for $30 \mathrm{~s}$, annealing at $55^{\circ} \mathrm{C}$ for $30 \mathrm{~s}$ and extension at $72{ }^{\circ} \mathrm{C}$ for $45 \mathrm{~s}$, with a final extension at $72{ }^{\circ} \mathrm{C}$ for $10 \mathrm{~min}$. Triplicate PCR products for each sample were pooled and purified using a PCR fragment purification kit (TaKaRa, Japan). The purified PCR products were assayed for fragment size with an Agilent 2100 (Agilent, USA) and quantified using a Quant-It Pico Green kit (Invitrogen, USA) and Qubit fluorometer (Life Technologies, USA). Equimolar amounts of PCR amplicons from each sample were pooled and then sequenced on a MiSeq platform (Illumina, USA). One larvae sample at the 14th and 22nd hour and two larvae samples at the 254th hour were failed to be amplified, and thus a total of 101 larvae samples and 92 water samples were sequenced.

\section{Sequence processing}

Raw FASTQ files were de-multiplexed with QIIME v1.9.1 [84], and the paired reads were joined using FLASH [85]. The merged sequences were quality filtered and processed with QIIME v1.9.1. Briefly, the sequences were qualityfiltered using the split_libraries_fastq.py script at Q20 [86]. The remaining sequences were chimera detected using UCHIME [87]. After removing the chimeras, the sequences were clustered into operational taxonomic units (OTUs, 97\% sequence similarity cutoff) using the pick_open_reference otus.py script with the Sortmerna_sumclust method $[88,89]$. The representative sequence (most abundant) of each OTU was taxonomically assigned against the SILVA 128 database [90] and aligned using PyNAST [84], respectively. A phylogenic tree was generated from the filtered alignment using FastTree [91]. Archaea, chloroplast, mitochondria, and singleton sequences were removed, as were the other sequences cannot be assigned to bacteria. The full dataset $(n=$ 193) after above procedures contained $6,878,394$ clean reads (mean 35,639 reads per sample). To normalize the sequencing depth, the OTU table was rarefied at 22,300 reads per sample for further analyses.

\section{General ecological and statistical analyses}

Alpha-diversity indices (Richness, Shannon-Wiener index, phylogenetic diversity) and $\beta$-diversity metrics (Bray-Curtis dissimilarity and weighted UniFrac distance) were calculated using QIIME. Pielou's evenness was calculated using the R package "vegan." Kruskal-Wallis analysis was applied to test the differences in bacterial $\alpha$-diversity of shrimp larvae or water among developmental stages using SPSS 22. Independent-sample $t$ test was applied to test the difference in bacterial $\alpha$-diversity between larvae and water at each stage. The heatmap of dominant OTUs (with average abundance > $2 \%$ at least in one sampling time point) were created using the R package "pheatmap" [92] to show the taxonomic succession of larval shrimp bacterial communities with host development, and the accessory phylogenetic tree was constructed using the maximum likelihood method in MEGA 7.0. The discriminatory taxa of each larval developmental stage were determined using linear discriminant analysis (LDA) effect size (LEfSe) [93], which employs the factorial Kruskal-Wallis sum-rank test $(\alpha=0.05)$ to identify taxa with significant differences in their relative abundance at the multiple levels among the stages (using one-against-all comparisons). 
Principal coordinates analysis (PCoA) based on BrayCurtis dissimilarity and weighted UniFrac distance was applied to visualize the overall taxonomic and phylogenetic turnover of larval or water bacterial community, respectively. Analysis of similarity (ANOSIM) was performed to test the significance of differences in larval/water bacterial communities between each pair of stages or between larval and water bacterial communities at each stage using PRIMER-E v5 (PRIMER-E Ltd., UK). The time-decay model was used to evaluate the temporal turnover rate of larval bacterial community across developmental stages as following:

$$
S=c T^{w}
$$

where $S$ represents the similarity of larval bacterial communities between samples over time, $T$ represents the duration between observations, and the scaling exponent $w$ is considered as an index of the temporal turnover rate of bacterial community and can be estimated with a linear regression based on a log-log scale:

$$
\log S=\log c+w \log T
$$

\section{Inference of assembly processes of larval shrimp bacteria by the neutral model}

The Sloan neutral model was used to infer the source of larval shrimp bacteria and the contribution of neutral processes (i.e., dispersal and ecological drift) to bacterial community assembly [43, 46]. For this purpose, we firstly assumed rearing water bacterioplankton as the source of larval bacterial communities. This neutral model predicts the relationship between the occurrence frequency of OTUs in larval bacterial communities and their abundance in the water bacterial communities. The goodness of model fitting was evaluated by $R^{2}$, when $0<$ $R^{2} \leq 1$, the water bacteria was considered to be (one of) the important sources of larval bacterial communities. The neutral model was further used to predict the relationship between the occurrence frequency of OTUs in the local larval bacterial communities and their abundance in the wider metacommunity (the communities of all larvae sampled at a given stage). When $0<R^{2} \leq 1$, the larval metacommunity was considered to be an important source of the local larval bacterial communities. In general, the model predicts that the species with high abundance in the metacommunity are more likely to disperse and be randomly sampled by hosts, while the species with low abundance are more likely to be lost from hosts due to ecological drift [46]. The $\mathrm{R}$ code from Burns et al. was used for neutral model fitting [46]. The 95\% confidence intervals around the fitting were calculated by bootstrapping with 1000 bootstrap replicates. In the model, the estimated migration rate $(m)$ was calculated using a non-linear least-squares fitting with the $\mathrm{R}$ package "minpack.lm" [46, 94], which is the probability that random loss of individuals in the local community will be replaced by dispersal from the metacommunity. Therefore, estimated migration rate can be interpreted as a measure of dispersal limitation, and higher $m$ values means less dispersal limited [46]. In addition, we used Akaike information criterion (AIC) for comparing the goodness of fit between the binomial distribution model and the neutral model [46]. The fit of binomial distribution model presents that microbial communities were assembled only by subsampling from metacommunity (species pool) [48]. Better fit of the neutral model suggests that additional drift and dispersal limitation also contribute to local community assembly other than dispersal [46]. The OTUs that fall within the 95\% confidence intervals of the best fit of the neutral model are considered as neutrally distributed. The OTUs that distribute above the $95 \%$ confidence interval (above prediction) are likely positively selected by the host or have a stronger dispersal ability relative to others. The OTUs that fall below the 95\% confidence interval (below prediction) are selected against by the host or dispersallimited from the source community.

\section{Functional prediction by PICRUSt2}

PICRUSt2 (Phylogenetic Investigation of Communities by Reconstruction of Observed States, v2.1.0-b) pipeline was used to infer functional potentials of larval shrimp microbiota [49]. The OTU table of larval bacteria was used for predicted 16S rRNA gene copy number normalization and the functional profiles were predicted using the script picrust2_pipeline.py, generating a table of Kyoto Encyclopedia of Genes and Genomes (KEGG) Orthologs (KOs). Default nearest-sequenced taxon index (NSTI) options were used to filter the unreliable KO predictions. KEGG Mapper was employed to reconstruct KEGG reference categories (KEGG level 1) and modules (KEGG level 2) according to the $\mathrm{KO}$ annotations [95]. Subsequently, the abundances of KEGG categories and modules of bacterial community or the family Rhodobacteraceae were inferred by $\mathrm{KO}$ abundances using the custom $\mathrm{R}$ scripts. Then the abundances of KEGG modules of bacterial community and the contribution of the family Rhodobacteraceae to functional potentials were visualized using the R package "pheatmap" [92].

\section{Supplementary information}

Supplementary information accompanies this paper at https://doi.org/10. 1186/s40168-020-00879-w.

Additional file 1: Table S1. Pairwise similarity test of bacterial communities between larval shrimp developmental stages. Table S2. Analysis of Similarity (ANOSIM) testing the differences between larval shrimp and rearing water bacterial communities. 
Additional file 2: Figure S1. Experimental design and sampling schedules. Figure S2. Dynamics of bacterial a-diversity and evenness indices of shrimp larvae and water across developmental stages. Figure S3. Linear discriminant analysis taxonomic cladogram showing discriminatory taxa at each developmental stage of shrimp larvae. Figure S4. Dynamics of bacterial community similarity among larvae samples and between larvae and water samples. Figure S5. The relationship between larval shrimp and water bacterial communities. Figure S6. Heatmaps showing the predicted function potentials of larval shrimp bacterial communities across the developmental stages.

\section{Acknowledgements}

The authors would like to thank Hainan Haiyue Aquaseed Co., Ltd. for providing facility and essential materials during the experiment.

\section{Authors' contributions}

$\mathrm{DZ}, \mathrm{ZL}$, and KW designed the study; YW, LH, SW, ZL, and DZ performed the study; KW and YW developed the data analysis strategy; $Y W, K W$, and PD analyzed the data; $\mathrm{HC}, \mathrm{DH}$ assisted with the analytic tools; $\mathrm{YW}$ and $\mathrm{KW}$ wrote the manuscript. All the authors reviewed and approved the manuscript.

\section{Funding}

This work is funded by Zhejiang Provincial Natural Science Foundation of China (LY18C030002), National Natural Science Foundation of China (31672658), Agricultural Major Project of Ningbo, China (2017C110001), the Basic Public Welfare Research Project of Zhejiang Province (LGN20C190008), and K.C. Wong Magna Fund in Ningbo University.

\section{Availability of data and materials}

The sequence data are available in the DDBJ Sequence Read Archive under accession number DRA009910 and DRA009911 (http//ddbj.nig.ac.jp/DRASearch)

\section{Ethics approval and consent to participate}

Not applicable.

\section{Consent for publication}

Not applicable.

\section{Competing interests}

The authors declare that they have no competing interests.

\section{Author details}

${ }^{1}$ State Key Laboratory for Managing Biotic and Chemical Threats to the Quality and Safety of Agro-products, Ningbo University, Ningbo 315211 China. ${ }^{2}$ School of Marine Sciences, Ningbo University, Ningbo 315211, China. ${ }^{3}$ School of Civil and Environmental Engineering, Ningbo University, Ningbo 315211, China. ${ }^{4}$ Huzhou Southern Taihu Lake Agricultural Biotechnology Institute, Huzhou 313000, China.

Received: 1 April 2020 Accepted: 8 June 2020

Published online: 03 July 2020

\section{References}

1. Matamoros S, Gras-Leguen C, Le Vacon F, Potel G, de La Cochetiere MF. Development of intestinal microbiota in infants and its impact on health. Trends Microbiol. 2013;21:167-73.

2. Bárcena C, Valdés-Mas R, Mayoral P, Garabaya C, Durand S, Rodríguez F, et al. Healthspan and lifespan extension by fecal microbiota transplantation into progeroid mice. Nat Med. 2019;25:1234-42.

3. Zokaeifar H, Luis Balcazar J, Saad CR, Kamarudin MS, Sijam K, Arshad A, et al. Effects of Bacillus subtilis on the growth performance, digestive enzymes, immune gene expression and disease resistance of white shrimp, Litopenaeus vannamei. Fish Shellfish Immunol. 2012;33:683-9.

4. Semova I, Carten JD, Stombaugh J, Mackey LC, Knight R, Farber SA, et al. Microbiota regulate intestinal absorption and metabolism of fatty acids in the zebrafish. Cell Host Microbe. 2012;12:277-88,

5. Ley RE, Bäckhed F, Turnbaugh P, Lozupone CA, Knight RD, Gordon Jl. Obesity alters gut microbial ecology. Proc Natl Acad Sci USA. 2005;102: 11070-5.
6. Round JL, Mazmanian SK. The gut microbiota shapes intestinal immune responses during health and disease. Nat Rev Immunol. 2009;9:313-23.

7. Nie L, Zhou Q, Qiao Y, Chen J. Interplay between the gut microbiota and immune responses of ayu (Plecoglossus altivelis) during Vibrio anguillarum infection. Fish Shellfish Immunol. 2017;68:479-87.

8. Bailey LC, Forrest CB, Zhang P, Richards TM, Livshits A, DeRusso PA. Association of antibiotics in infancy with early childhood obesity. JAMA Pediatr. 2014;168:1063-9.

9. Kronman MP, Zaoutis TE, Haynes K, Feng R, Coffin SE. Antibiotic exposure and IBD development among children: a population-based cohort study. Pediatrics. 2012;130:e794-803.

10. Maynard $\mathrm{CL}$, Elson $\mathrm{CO}$, Hatton $\mathrm{RD}$, Weaver $\mathrm{CT}$. Reciprocal interactions of the intestinal microbiota and immune system. Nature. 2012;489:231-41.

11. Tamburini S, Shen N, Wu HC, Clemente JC. The microbiome in early life: implications for health outcomes. Nat Med. 2016;22:713-22.

12. Xiong J, Dai W, Zhu J, Liu K, Dong C, Qiu Q. The underlying ecological processes of gut microbiota among cohabitating retarded, overgrown and normal shrimp. Microb Ecol. 2017;73:988-99.

13. Liu J, Wang K, Wang Y, Chen W, Jin Z, Yao Z, et al. Strain-specific changes in the gut microbiota profiles of the white shrimp Litopenaeus vannamei in response to cold stress. Aquaculture. 2019:503:357-66.

14. Rungrassamee W, Klanchui A, Maibunkaew S, Karoonuthaisiri N. Bacteria dynamics in intestines of the black tiger shrimp and the Pacific white shrimp during Vibrio harveyi exposure. J Invertebr Pathol. 2016;133:12-9.

15. Xiong J, Wang K, Wu J, Qiuqian L, Yang K, Qian Y, et al. Changes in intestinal bacterial communities are closely associated with shrimp disease severity. Appl Microbiol Biotechnol. 2015;99:6911-9.

16. Hou D, Huang Z, Zeng S, Liu J, Wei D, Deng X, et al. Intestinal bacterial signatures of white feces syndrome in shrimp. Appl Microbiol Biotechnol. 2018;102:3701-9.

17. Xiong J, Dai W, Qiu Q, Zhu J, Yang W, Li C. Response of host-bacterial colonization in shrimp to developmental stage, environment and disease. Mol Ecol. 2018;27:3686-99.

18. FAO. Global aquaculture production 1950-2017. 2019. http://www.fao.org/ fishery/statistics/global-aquaculture-production/query/en.

19. Thitamadee S, Prachumwat A, Srisala J, Jaroenlak P, Salachan PV, Sritunyalucksana K, et al. Review of current disease threats for cultivated penaeid shrimp in Asia. Aquaculture. 2016;452:69-87.

20. Xiong J, Dai W, Li C. Advances, challenges, and directions in shrimp disease control: the guidelines from an ecological perspective. Appl Microbiol Biotechnol. 2016;100:6947-54.

21. Lin J, Pang D. Analysis of the reasons for the decline of the germplasm of Penaeus vannamei and its countermeasures. Chin J Fish. 2002:83-4 (in Chinese).

22. Zhu J, Dai W, Qiu Q, Dong C, Zhang J, Xiong J. Contrasting ecological processes and functional compositions between intestinal bacterial community in healthy and diseased shrimp. Microb Ecol. 2016;72:975-85.

23. Xiong J, Zhu J, Dai W, Dong C, Qiu Q, Li C. Integrating gut microbiota immaturity and disease-discriminatory taxa to diagnose the initiation and severity of shrimp disease. Environ Microbiol. 2017;19:1490-501.

24. Huang Z, Zeng S, Xiong J, Hou D, Zhou R, Xing C, et al. Microecological Koch's postulates reveal that intestinal microbiota dysbiosis contributes to shrimp white feces syndrome. Microbiome. 2020:8:32.

25. Dai W, Yu W, Zhang J, Zhu J, Tao Z, Xiong J. The gut eukaryotic microbiota influences the growth performance among cohabitating shrimp. App Microbiol Biotechnol. 2017;101:6447-57

26. Dai W, Zhang J, Qiu Q, Chen J, Yang W, Ni S, et al. Starvation stress affects the interplay among shrimp gut microbiota, digestion and immune activities. Fish Shellfish Immunol. 2018;80:191-9.

27. Rungrassamee W, Klanchui A, Chaiyapechara S, Maibunkaew S, Tangphatsornruang S, Jiravanichpaisal P, et al. Bacterial population in intestines of the black tiger shrimp (Penaeus monodon) under different growth stages. PLoS One. 2013;8:e60802.

28. Huang Z, Li X, Wang L, Shao Z. Changes in the intestinal bacterial community during the growth of white shrimp, Litopenaeus vannamei. Aquac Res. 2016:47:1737-46.

29. Zeng S, Huang Z, Hou D, Liu J, Weng S, He J. Composition, diversity and function of intestinal microbiota in pacific white shrimp (Litopenaeus vannamei) at different culture stages. PeerJ. 2017;5:e3986

30. Estefanía G-V, Marcel M-P, Kadiya C, Francisco V-A, Teresa G-G, Luis M-C. Taxonomic and functional changes in the microbiota of the white shrimp (Litopenaeus vannamei) associated with postlarval ontogenetic development. Aquaculture. 2020;518:734842. 
31. Tzeng TD, Pao YY, Chen PC, Weng FCH, Jean WD, Wang D. Effects of host phylogeny and habitats on gut microbiomes of oriental river prawn (Macrobrachium nipponense). PLoS One. 2015;10:e0132860.

32. Rungrassamee W, Klanchui A, Maibunkaew S, Chaiyapechara S, Jiravanichpaisal P, Karoonuthaisiri N. Characterization of intestinal bacteria in wild and domesticated adult black tiger shrimp (Penaeus monodon). PLoS One. 2014;9:e91853.

33. Zhang M, Sun Y, Liu Y, Qiao F, Chen L, Liu WT, et al. Response of gut microbiota to salinity change in two euryhaline aquatic animals with reverse salinity preference. Aquaculture. 2016;454:72-80.

34. Li E, Xu C, Wang X, Wang S, Zhao Q, Zhang M, et al. Gut microbiota and its modulation for healthy farming of Pacific white shrimp Litopenaeus vannamei. Rev Fish Sci Aquac. 2018;26:381-99.

35. Qiao F, Liu Y, Sun Y, Wang X, Chen K, Li T, et al. Influence of different dietary carbohydrate sources on the growth and intestinal microbiota of Litopenaeus vannamei at low salinity. Aquac Nutr. 2017;23:444-52.

36. Yao Z, Yang K, Huang L, Huang X, Qiuqian L, Wang K, et al. Disease outbreak accompanies the dispersive structure of shrimp gut bacterial community with a simple core microbiota. AMB Expr. 2018;8:120.

37. Dai W, Yu W, Xuan L, Tao Z, Xiong J. Integrating molecular and ecological approaches to identify potential polymicrobial pathogens over a shrimp disease progression. Appl Microbiol Biotechnol. 2018;102:3755-64.

38. Xiong J, Xuan L, Yu W, Zhu J, Qiu Q, Chen J. Spatiotemporal successions of shrimp gut microbial colonization: high consistency despite distinct species pool. Environ Microbiol. 2019;21:1383-94.

39. Zhao Y, Duan C, Zhang X, Chen H, Ren H, Yin Y, et al. Insights into the gut microbiota of freshwater shrimp and its associations with the surrounding microbiota and environmental factors. J Microbiol Biotechnol. 2018;28:946-56.

40. Zheng Y, Yu M, Liu Y, Su Y, Xu T, Yu M, et al. Comparison of cultivable bacterial communities associated with Pacific white shrimp (Litopenaeus vannamei) larvae at different health statuses and growth stages. Aquaculture. 2016;451:163-9.

41. Zheng Y, Yu M, Liu J, Qiao Y, Wang L, Li Z, et al. Bacterial community associated with healthy and diseased Pacific white shrimp (Litopenaeus vannamei) larvae and rearing water across different growth stages. Front Microbiol. 2017:8:1362.

42. Xue $M$, Wu L, He $Y$, Liang $H$, Wen $C$. Biases during DNA extraction affect characterization of the microbiota associated with larvae of the Pacific white shrimp, Litopenaeus vannamei. PeerJ. 2018;6:e5257.

43. Venkataraman A, Bassis CM, Beck JM, Young VB, Curtis JL, Huffnagle GB, et al. Application of a neutral community model to assess structuring of the human lung microbiome. mBio. 2015;6:e02284-14.

44. Zhou J, Ning D. Stochastic community assembly: does it matter in microbial ecology? Microbiol Mol Biol Rev. 2017;81:e00002-17.

45. Adair KL, Wilson M, Bost A, Douglas AE. Microbial community assembly in wild populations of the fruit fly Drosophila melanogaster. ISME J. 2018;12:959-72.

46. Burns AR, Stephens WZ, Stagaman K, Wong S, Rawls JF, Guillemin K, et al. Contribution of neutral processes to the assembly of gut microbial communities in the zebrafish over host development. ISME J. 2016;10:655-64.

47. Sloan WT, Lunn M, Woodcock S, Head IM, Nee S, Curtis TP. Quantifying the roles of immigration and chance in shaping prokaryote community structure. Environ Microbiol. 2006;8:732-40.

48. Sloan WT, Woodcock S, Lunn M, Head IM, Curtis TP. Modeling taxaabundance distributions in microbial communities using environmental sequence data. Microb Ecol. 2007;53:443-55.

49. Douglas GM, Maffei VJ, Zaneveld JR, Yurgel SN, Brown JR, Taylor CM, et al. PICRUSt2 for prediction of metagenome functions. Nat Biotechnol. 2020;38: 685-8.

50. Bakke I, Coward E, Andersen T, Vadstein O. Selection in the host structures the microbiota associated with developing cod larvae (Gadus morhua). Environ Microbiol. 2015;17:3914-24

51. Li X, Zhou L, Yu Y, Ni J, Xu W, Yan Q. Composition of gut microbiota in the gibel carp (Carassius auratus gibelio) varies with host development. Microb Ecol. 2017;74:239-49.

52. Zhang Z, Li D, Refaey MM, Xu W, Tang R, Li L. Host age affects the development of southern catfish gut bacterial community divergent from that in the food and rearing water. Front Microbiol. 2018;9:495.

53. Stephens WZ, Burns AR, Stagaman K, Wong S, Rawls JF, Guillemin K, et al. The composition of the zebrafish intestinal microbial community varies across development. ISME J. 2016;10:644-54.

54. Yan Q, van der Gast CJ, Yu Y. Bacterial community assembly and turnover within the intestines of developing zebrafish. PLoS One. 2012;7:e30603.
55. Romero J, Navarrete P. 165 rDNA-based analysis of dominant bacterial populations associated with early life stages of coho salmon (Oncorhynchus kisutch). Microb Ecol. 2006;51:422-30.

56. Vandenberghe J, Verdonck L, Robles-Arozarena R, Rivera G, Bolland A, Balladares M, et al. Vibrios associated with Litopenaeus vannamei larvae, postlanvae, broodstock, and hatchery probionts. Appl Environ Microbiol. 1999;65:2592-7.

57. Kumar TS, Vidya R, Kumar S, Alavandi SV, Vijayan KK. Zoea-2 syndrome of Penaeus vannamei in shrimp hatcheries. Aquaculture. 2017:479:759-67.

58. McGrady-Steed J, Harris PM, Morin PJ. Biodiversity regulates ecosystem predictability. Nature. 1997;390:162-5.

59. Ptacnik R, Solimini AG, Andersen T, Tamminen T, Brettum P, Lepistö L, et al. Diversity predicts stability and resource use efficiency in natural phytoplankton communities. Proc Natl Acad Sci USA. 2008;105:5134-8.

60. Shade A. Diversity is the question, not the answer. ISME J. 2017;11:1-6.

61. Shanahan F. Probiotics in perspective. Gastroenterology. 2010;139:1808-12.

62. Costello EK, Gordon Jl, Secor SM, Knight R. Postprandial remodeling of the gut microbiota in Burmese pythons. ISME J. 2010:4:1375-85.

63. Xiong J, Yu W, Dai W, Zhang J, Qiu Q, Ou C. Quantitative prediction of shrimp disease incidence via the profiles of gut eukaryotic microbiota. Appl Microbiol Biotechnol. 2018;102:3315-26.

64. Zhang J, Duan Y, Zhang Z, Dong H, Li Z. Research progress of intestinal microbial flora in shrimp. S China Fish Sci. 2015;11:114-9 (in Chinese).

65. Yan Q, Li J, Yu Y, Wang J, He Z, Van Nostrand JD, et al. Environmental filtering decreases with fish development for the assembly of gut microbiota. Environ Microbiol. 2016;18:4739-54.

66. Greenhalgh K, Meyer KM, Aagaard KM, Wilmes P. The human gut microbiome in health: establishment and resilience of microbiota over a lifetime. Environ Microbiol. 2016;18:2103-16.

67. Wong S, Stephens WZ, Burns AR, Stagaman K, David LA, Bohannan BJM, et al. Ontogenetic differences in dietary fat influence microbiota assembly in the zebrafish gut. mBio. 2015;6:e00687-15.

68. Mata MT, Luza MF, Riquelme CE. Production of diatom-bacteria biofilm isolated from Seriola lalandi cultures for aquaculture application. Aquac Res. 2017:48:4308-20.

69. Giebel HA, Klotz F, Voget S, Poehlein A, Grosser K, Teske A, et al. Draft genome sequence of the marine Rhodobacteraceae strain $\mathrm{O3.65}$, cultivated from oil-polluted seawater of the Deepwater Horizon oil spill. Stand Genomic Sci. 2016:11:81.

70. Buchan A, González JM, Chua MJ. Aerobic Hydrocarbon-Degrading Alphaproteobacteria: Rhodobacteraceae (Roseobacter). In: Mcgenity TJ, editor. Taxonomy, genomics and ecophysiology of hydrocarbon-degrading microbes. Cham: Springer; 2019. p. 1-13.

71. Sañudo-Wilhelmy SA, Gómez-Consarnau L, Suffridge C, Webb EA. The role of B vitamins in marine biogeochemistry. Ann Rev Mar Sci. 2014;6:339-67.

72. Sharifah EN, Eguchi M. The phytoplankton Nannochloropsis oculata enhances the ability of Roseobacter clade bacteria to inhibit the growth of fish pathogen Vibrio anguillarum. PLoS One. 2011;6:e26756.

73. Gromek SM, Suria AM, Fullmer MS, Garcia JL, Gogarten JP, Nyholm SV, et al. Leisingera sp. JC1, a bacterial isolate from Hawaiian bobtail squid eggs, produces indigoidine and differentially inhibits vibrios. Front Microbiol. 2016;7:1342.

74. Sonnenschein EC, Nielsen KF, D'Alvise P, Porsby CH, Melchiorsen J, Heilmann J, et al. Global occurrence and heterogeneity of the Roseobacterclade species Ruegeria mobilis. ISME J. 2017;11:569-83.

75. Porsby CH, Nielsen KF, Gram L. Phaeobacter and Ruegeria species of the Roseobacter clade colonize separate niches in a Danish turbot (Scophthalmus maximus)-rearing farm and antagonize Vibrio anguillarum under different growth conditions. Appl Environ Microbiol. 2008;74:7356-64.

76. D'Alvise PW, Lillebø S, Wergeland HI, Gram L, Bergh $\varnothing$. Protection of cod larvae from vibriosis by Phaeobacter spp.: a comparison of strains and introduction times. Aquaculture. 2013;384-387:82-6.

77. Huang L, Guo H, Chen C, Huang X, Chen W, Bao F, et al. The bacteria from large-sized bioflocs are more associated with the shrimp gut microbiota in culture system. Aquaculture. 2020;523:735159.

78. Kulecka M, Paziewska A, Zeber-Lubecka N, Ambrozkiewicz F, Kopczynski M, Kuklinska $U$, et al. Prolonged transfer of feces from the lean mice modulates gut microbiota in obese mice. Nutr Metab. 2016;13:57.

79. Bäckhed F, Roswall J, Peng Y, Feng Q, Jia H, Kovatcheva-Datchary P, et al. Dynamics and stabilization of the human gut microbiome during the first year of life. Cell Host Microbe. 2015;17:690-703.

80. Dominguez-Bello MG, Costello EK, Contreras M, Magris M, Hidalgo G, Fierer $\mathrm{N}$, et al. Delivery mode shapes the acquisition and structure of the initial 
microbiota across multiple body habitats in newborns. Proc Natl Acad Sci USA. 2010;107:11971-5.

81. Loudon AH, Venkataraman A, Van Treuren W, Woodhams DC, Parfrey LW, McKenzie VJ, et al. Vertebrate hosts as islands: dynamics of selection, immigration, loss, persistence, and potential function of bacteria on salamander skin. Front Microbiol. 2016;7:333.

82. Apprill A, McNally S, Parsons R, Weber L. Minor revision to V4 region SSU rRNA 806R gene primer greatly increases detection of SAR11 bacterioplankton. Aquat Microb Ecol. 2015;75:129-37.

83. Walters W, Hyde ER, Berg-Lyons D, Ackermann G, Humphrey G, Parada A, et al. Improved bacterial 16S rRNA gene (V4 and V4-5) and fungal internal transcribed spacer marker gene primers for microbial community surveys. mSystems. 2016;1:e00009-15.

84. Caporaso JG, Kuczynski J, Stombaugh J, Bittinger K, Bushman FD, Costello EK, et al. QIIME allows analysis of high-throughput community sequencing data. Nat Methods. 2010;7:335-6.

85. Magoč T, Salzberg SL. FLASH: fast length adjustment of short reads to improve genome assemblies. Bioinformatics. 2011;27:2957-63.

86. Bokulich NA, Subramanian S, Faith JJ, Gevers D, Gordon JI, Knight R, et al. Quality-filtering vastly improves diversity estimates from Illumina amplicon sequencing. Nat Methods. 2013;10:57-9.

87. Edgar RC. Search and clustering orders of magnitude faster than BLAST. Bioinformatics. 2010;26:2460-1.

88. Kopylova E, Noé L, Touzet H. SortMeRNA: fast and accurate filtering of ribosomal RNAs in metatranscriptomic data. Bioinformatics. 2012;28:3211-7.

89. Mercier C, Boyer F, Bonin A, Coissac É. SUMATRA and SUMACLUST: fast and exact comparison and clustering of sequences.// Programs and Abstracts of the SeqBio 2013 workshop (Abstract). Montpellier; 2013. p. 27-9. Available at http://metabarcoding.org/sumatra.

90. Quast C, Pruesse E, Yilmaz P, Gerken J, Schweer T, Yarza P, et al. The SILVA ribosomal RNA gene database project: improved data processing and webbased tools. Nucleic Acids Res. 2013;41:D590-D6.

91. Price MN, Dehal PS, Arkin AP. FastTree 2-approximately maximumlikelihood trees for large alignments. PLoS One. 2010;5:e9490.

92. Kolde R. pheatmap: pretty heatmaps. R package version 1.0.8. 2015. https:// CRAN.R-project.org/package=pheatmap.

93. Segata N, lzard J, Waldron L, Gevers D, Miropolsky L, Garrett WS, et al. Metagenomic biomarker discovery and explanation. Genome Biol. 2011;12:R60.

94. Elzhov TV, Mullen KM, Spiess AN, Bolker B. minpack.Im: R interface to the Levenberg-Marquardt nonlinear least-squares algorithm found in MINPACK, plus support for bounds. R package version 1.2-1. 2013. https://CRAN.Rproject.org $/$ package $=$ minpack. Im.

95. Kanehisa M, Sato Y. KEGG Mapper for inferring cellular functions from protein sequences. Protein Sci. 2020;29:28-35.

\section{Publisher's Note}

Springer Nature remains neutral with regard to jurisdictional claims in published maps and institutional affiliations.

Ready to submit your research? Choose BMC and benefit from:

- fast, convenient online submission

- thorough peer review by experienced researchers in your field

- rapid publication on acceptance

- support for research data, including large and complex data types

- gold Open Access which fosters wider collaboration and increased citations

- maximum visibility for your research: over $100 \mathrm{M}$ website views per year

At BMC, research is always in progress.

Learn more biomedcentral.com/submissions 